\title{
Isadora Duncan por Rubén Darío. Reflexiones sobre la recepción argentina de Duncan
}

\author{
Isadora Duncan by Rubén Darío. Reflections on the argentine \\ reception of Duncan
}

Eugenia Cadús eugeniacadus@gmail.com

http://orcid.org/0000-0002-0918-9095

Instituto de Historia del Arte Argentino y Latinoamericano;

Facultad de Filosofía y Letras; Universidad de Buenos Aires/ Consejo Nacional de Investigaciones Científicas y Técnicas (Argentina)

\section{Resumen}

El artículo analiza comparativamente la figura del escritor Rubén Darío -tomándolo como representante de la intelectualidad porteña de la época- y la de la bailarina Isadora Duncan, a partir de los textos de ambos así como sus concepciones artísticas e ideológicas, haciendo énfasis en la noción de modernismo. Se trata de un trabajo inicial sobre la conformación de un "gusto modernista" en el público de danza argentino de principios del siglo XX. El artículo analiza las presentaciones de Duncan en Buenos Aires y su repercusión en la prensa escrita de la época para reconstruir la recepción de la bailarina por parte del público local. En este punto, se rastrea el modo en que la historiografía de la danza argentina ha retomado lecturas de la prensa del momento, incluso dichos de Darío sobre Duncan, y los ha reproducido de manera acrítica. Así se sostuvo la imagen de Duncan como "rara" e irreverente, aunque para 
1916 su estética ya no lo era y por ello el público y la prensa local, que conocía en profundidad su poética, calificó su danza como un arte que "ya no conmueve a nadie".

Palabras clave: Isadora Duncan; Rubén Darío; modernismo; espectadores; Argentina; danza.

\section{Abstract}

The article is a comparative analysis of writer Rubén Darío and dancer Isadora Duncan. Taking Darío as a representative figure of the Buenos Aires intellectuality of the time, this study is based on texts of both figures and their artistic and ideological ideas, and makes an emphasis on the notion of modernism. This is an initial work on the conformation of a "modernist taste" in the Argentine dance audience of the early twentieth century. To reconstruct the reception of the dancer by the local audience, the article analyzes Duncan's performances in Buenos Aires and its repercussion in the written press of the time. The research traces the way in which the historiography of the Argentine dance has taken up the press statements of the moment, and even Darío's sayings about Duncan, and has uncritically reproduced them. This way, Duncan image was held as "rare" and irreverent, although by 1916, her aesthetic was no longer so rebellious, and for that reason the audience and the local press, who deeply knew her poetics, described Duncan's dance as an art that "it no longer moves anyone".

Keywords: Isadora Duncan; Rubén Darío; modernism; audience; Argentina; dance.

En 1903, en el teatro Sarah Bernhardt de París, el escritor Rubén Darío asistió a una presentación de la bailarina Isadora Duncan. Allí se generó un encuentro estético que por parte de Darío culminó en dos escritos: por un lado, la crónica acerca de la presentación de Duncan titulada "Miss Isadora Duncan" y publicada el 13 de agosto de 1903 en el Suplemento llustrado del diario argentino La Nación; y por el otro, el poema "La bailarina de los pies desnudos" publicado en El Canto Errante en 1907.

La crónica "Miss Isadora Duncan" fue quizás uno de los primeros vínculos que muchos de los lectores argentinos de este diario tuvieron con la bailarina. A través de la prensa gráfica, llegaban las novedades parisinas, y entre estas lecturas y los viajes de la élite intelectual argentina a la capital francesa -entre otros factores-, se iría configurando un determinado gusto en los espectadores locales de danza. 
El presente artículo se trata de un trabajo inicial y de carácter exploratorio acerca de las figuras de Darío y Duncan y de cómo se conforma un "gusto modernista" en el público de danza argentino de principios del siglo XX. Queremos indagar en aquellos agentes y "formaciones culturales" (Williams, 2000) que fueron construyendo este "horizonte de expectación" (Jauss, 1976). Asimismo la investigación abarca un debate más amplio que se abordará aquí de modo parcial, acerca de las diferencias -en este contexto- entre moderno, Modernidad y modernismo. Para ello, en esta primera instancia analizamos las presentaciones en Buenos Aires de la bailarina "moderna" Isadora Duncan y su repercusión en la prensa escrita de la época. Asimismo, delineamos las características del modernismo en perspectiva comparativa, en la literatura y en la danza y su expresión en la Argentina a partir de los escritos de Darío, tomándolo como un intelectual representativo de la época. A modo de ejemplo, cabe recordar que entre otros intelectuales, el escritor modernista latinoamericano César Vallejo también dedicó palabras a Duncan en 1927 en su artículo "Los funerales de Isadora Duncan" para el periódico limeño Mundial.

La cultura de élite conformada por la oligarquía porteña de fines del 1800 y principios del 1900 pretendía que Buenos Aires y por ende la Argentina, fuese reconocida como la nación más "moderna" entre los países latinoamericanos, por lo tanto consideraron que le correspondía una danza de escena que se distinguiera de los gustos populares -el circo, el folklore y el tango(Pasolini, 1999). Así, la danza entendida como "arte culto" se construyó bajo la influencia cultural de la modernidad eurocentrada; dignas representaciones de este arte fue el ballet moderno según el modelo francés (1) y posteriormente, una modern dance que seguía la novedad proveniente de Estados Unidos (2) (Tambutti, 2011). Desde 1913 se comienza a gestar la práctica de la danza argentina, en la que los distintos agentes se iban formando como productores y como espectadores de este arte, de la mano de los "expertos" extranjeros previamente legitimados en París (Cadús, 2017).

A partir de estas premisas iniciamos nuestra investigación, indagando sobre cómo se va conformando la práctica de la danza argentina, entre fines del siglo XIX y la primera mitad del siglo $X X$, y qué implicancias tiene ese origen hasta el día de hoy. En el presente artículo analizaremos un agente que la historiografía de la danza ha considerado central en la construcción de una estética moderna: Isadora Duncan. Realizamos un diálogo comparativo entre literatura y danza para indagar en la categoría estética de modernismo. Asimismo, efectuamos la reconstrucción histórica crítica, por medio de fuentes gráficas, de la visita de Duncan a la Argentina y de los relatos construidos alrededor de esta. 
En una primera parte examinamos la cuestión del modernismo. Expondremos las características comunes a Duncan y Darío, así como aquellas que los diferencian. Para ello trabajamos con los escritos de ambos artistas, analizando sus concepciones estéticas e ideológicas. Observamos que si bien comparten varios rasgos y posicionamientos, se diferencian en el motor que mueve sus búsquedas artísticas, siendo el principal valor que exalta Duncan el de la libertad -la experimentación y la inspiración-, característica del romanticismo, a diferencia del modernismo de Darío. Sin embargo, encontramos sus principales coincidencias en relación a un contexto social, político y cultural en común.

De este modo, intentamos reconstruir el interés que generó la bailarina para la élite intelectual argentina de principios del siglo XX. Recordemos las propias palabras de Darío, quien en su crónica hace alusión a los intelectuales locales que se verían interesados en la danza de Duncan en la frase: "Y he pensado en lo que lo disfrutaría mi ilustre amigo Guido Spano ante esta Gracia danzante, antigua griega de carne viva" (1920: 153). Por medio de Darío, a quien tomamos como un representante de esta intelectualidad, nos proponemos ensayar la reconstrucción del imaginario de Duncan creado previo a su visita, para luego estudiar su llegada al país trece años después de la crónica periodística escrita por él.

En el segundo apartado, analizaremos la recepción local de las presentaciones de Duncan en Buenos Aires en julio de 1916, a través de la prensa gráfica. En este análisis, rastreamos el modo en que la crítica actual ha retomado lecturas de la prensa de aquel contexto y las ha reproducido de manera acrítica.

En un ejercicio de reconstrucción histórica, buscando contribuir a la creación de una historia social/cultural de la danza escénica argentina, indagamos críticamente en esta visita. Para ello, nos servimos de los diarios de la época que se conservan en la Hemeroteca de la Biblioteca del Congreso de la Nación Argentina: La Nación, La Época y El Diario. Es decir, reconstruimos su visita a través de los medios gráficos y las impresiones periodísticas, a sabiendas de que esta reconstrucción será parcial. Por ello indagamos en la construcción de la figura de Duncan a través de los diarios y de la intelectualidad porteña -representada parcialmente en la figura de Darío-, y para complementar dicha mirada utilizamos los escritos de la propia Duncan, su autobiografía Mi Vida (2006) y la biografía escrita por Frederika Blair (1989).

\section{Notas sobre el modernismo}


En "Modernismo e ideologías" Carlos Real de Azúa (1986) sintetiza algunas de las características definitorias del modernismo en la literatura latinoamericana: la búsqueda de la originalidad y la personalización de la obra; la "voluntad de belleza"; la aversión al realismo, a todo lo práctico y a la sobrerrealidad, al sueño, a la eterealización de lo real a través del arte; el atractivo por las "situaciones-límite" en nombre de la experiencia, la veta "decadentista"; el regodeo en lo "selecto", "refinado", "aristocrático"; el exotismo, el interés por culturas muy alejadas en el tiempo; la búsqueda de perfección en la escritura “(...) enriquecida lingüística y sintácticamente por cualidades de eufonía, ritmo, relieve y color dentro de estilos personales que valoran como metas de calificación la sugestión, el matiz, la rareza, la levedad, la innovación de formas y estructuras (especialmente poéticas)" (1986: iii-iv).

Aunque podemos identificar algunos puntos en común con la danza de fines del siglo XIX y principios del XX, cuyos protagonistas -entre los que se incluye Duncan- fueron denominados "precursores de la danza moderna", observamos que si bien existe una renovación en la danza caracterizada por una aversión al academicismo del ballet (3), la misma no alcanza el nivel de criticidad y auto reflexión sobre el medio que requiere el modernismo.

La necesidad de cambio evidenciada por las nuevas propuestas estéticas de la danza producida entre 1890 y 1914, fue acompañada por un sentimiento de nostalgia expresado en un imaginario que hundía sus raíces en los programas artísticos del romanticismo alemán. Los primeros movimientos artísticos renovadores adoptaron diversas denominaciones: danza libre, danza de los pies descalzos, danza absoluta, etcétera. Intentaban dar cuenta de los nuevos imperativos artísticos presentes en una danza que comenzaba a formar parte del entorno moderno, evidenciando un quiebre con el pasado y mostrando el comienzo de un proceso de experimentación (Tambuttti, 2014).

Para estos bailarines el valor que primaba en la experimentación era el de la libertad, exaltando la inspiración repentina. Como señala Real de Azúa, la libertad es un valor característico del romanticismo, mientras que los valores multívocos del modernismo son el universalismo, el cosmopolitismo, el profundo "personalismo" y aun "anarquismo" creativo, "la voluntad de invención, renovación y refinamiento verbales", el idealismo, "la fuerte acentuación erótica, el evasionismo, el exotismo, la busca de situaciones límites en términos psíquicos o éticos, la abierta primacía dada a la belleza (...)" (1986: x). En el caso de Darío y Duncan podemos decir que a pesar de que comparten varios rasgos, los impulsos y valores son distintos, lo que marca sus diferencias respecto a su estética, pudiendo emplazarse el primero en el modernismo y la segunda en el romanticismo. 
En primer lugar, observamos una característica determinante en estos dos artistas: la búsqueda de lo nuevo. Para ambos la renovación se encontraba en el pasado. En esta empresa Darío recuperó los "raros" y del mismo modo calificó a Duncan en su crónica, concentrando su rareza en su pie desnudo: "El cuerpo es soberbio, y cuando se presenta triunfa de algo verdaderamente delicado: la dificultad, la rareza de encontrar un pie perfecto" (1920: 152). De hecho, el siguiente escrito dedicado a Duncan será precisamente sobre sus pies. Tal como señala Marcela Croce (2013), una marca distintiva del modernismo es la descripción de la figura femenina como un objeto artístico y el punto de partida del recorrido sobre sus cuerpos es el pie.

Sin embargo, a diferencia de las demás mujeres darianas, quizás por su categoría de artista y de "rara", Duncan no carece de alma y su belleza, para Darío, es modernista: "Es nuevo y es bello, de encantadora belleza, ese resucitar de viejas visiones" (1920: 150). Duncan entendía a la danza del mismo modo, expresando en uno de sus escritos más emblemáticos, la conferencia "La danza del futuro" pronunciada en Berlín en 1903, texto que Darío insinúa conocer (Darío, 1920: 151-152): "Si indagamos en el verdadero origen de la danza, si vamos a la naturaleza, encontraremos que la danza del futuro es la danza del pasado, la danza de la eternidad, y ha sido y siempre será la misma" (Duncan, 2003: 55).

Ahora bien, tras esta "rareza" de Duncan reside otra característica que el modernismo comparte con la danza de la época, a saber: el arte como una fe de círculo, de iniciados. Croce (2013) define a Darío como partícipe de una fe laica en la que el poeta se postula como un sacerdote. Asimismo se definen los bailarines de la danza libre. Isadora conjuga una espiritualidad cristiana con una devoción hacia el arte de la Antigua Grecia y fue llamada "la divina y santa Isadora". Ella consideraba su danza como una oración, expresando por ejemplo: "Es una oración esta danza; cada movimiento alcanza con largas ondulaciones el cielo y se convierte en parte del ritmo eterno de las esferas" (Duncan, 2003: 57); y su escuela como un templo (Duncan, 2006: 321-322) (4).

Según Susana Tambutti (2014) en esta búsqueda de una nueva religiosidad estaba presente la necesidad de legitimar una danza que había caído en el entretenimiento -en referencia al ballet-. Esta postura se enfrentaba a la figura del burgués que acumula riqueza material mientras que el artista distribuye la riqueza estética: "Porque el arte que no es religioso, no es arte, es pura mercadería”, expresaba Duncan (2003: 63).

En el mismo sentido podemos leer el poema "Divagación" de Darío. Aquí, una élite artística se enfrenta al burgués que "no sabe nada". Además, en la crónica "Miss Isadora Duncan", tras reconocer que es "digna de entusiasmo esa rítmica yanqui que hace poesía y arte con la gracia 
de su cuerpo", y definir a la bailarina como "ninfa, sacerdotisa y musa" y moderna, señala que el público parisino no sabe reconocerla:

París no ha correspondido a la novedad, porque la Prensa estuvo seca por culpa, dicen, del empresario. Mas no faltaron los novedosos de siempre, los snobs, tales princesas y tales artistas, amén de la colonia, que siempre está dispuesta a apoyar todo lo que viene del país poderoso en donde, si hay gigantes Morganes y Rockefellers, surgen hadas Loïs (5) e Isadoras (Darío, 1920: 149-150).

Y agrega que "(...) un buen señor de negocios, que va al teatro a hacer su digestión, quizás encontrará todo eso absurdo o se fijará en cosas que no son propiamente el sutil hechizo de esta obra y de este acto de arte" (152).

Esta idea de incomprensión por parte del público se va a replicar luego en el relato construido por la historiografía de la danza argentina acerca de la visita de Isadora, pero como veremos en el próximo apartado, esto no fue necesariamente así, sino que se han repetido acríticamente las versiones de la propia Duncan y de su biógrafa, Blair.

Según los escritos de Darío, aquello que no saben reconocer los burgueses es el modernismo, la novedad y la belleza cimentada en el pasado. Este pasado corresponde con frecuencia al clasicismo griego y su humanismo. Sin embargo, el acceso a esa cultura por parte de los escritores modernistas, al igual que el público porteño de danza de la época, se da a través de Francia como observamos en el poema de Darío "A Francia", por ejemplo, y en el anteriormente mencionado "Divagación", cuando escribe "Amo más que la Grecia de los griegos a la Grecia de la Francia" (Croce, 2013: 26). Asimismo Darío recurre -no erradamentea la tradición greco-romana para analizar la danza de Duncan tanto en el poema dedicado a la bailarina - $¡ Y$ era toda Setene y Anactoria la bailarina de los pies desnudos!" (1924: 35)- como en su crónica, la cual inicia haciendo referencia a esto: "Canta, oh musa, a Isadora, la de los pies desnudos, y sus danzas ultramodernas de puro arcaicas, y sus piernas de Diana, y las músicas antiguas que acompañan las danzas (...)" (1920: 149). Y más adelante describe la semi desnudez de Isadora como evocadora de la mitología griega, la compara con Eurídice, Eco y Ariadna, y la llama "Gracia danzante, antigua griega de carne viva" (153). En este sentido, veremos en el próximo apartado, fue comprendida la "desnudez" de Duncan por parte de la prensa y probablemente de los espectadores locales en Buenos Aires en 1916.

Noel Rivas Bravo (1998) señala que el poema está inspirado en las teorías de Nietzsche sobre la lírica dionisíaca, según la cual el "yo" lírico adquiere una dimensión sobrenatural, llega a 
sentirse Dios por un proceso de transfiguración del sujeto lírico. "Digamos que no es Darío quien ve bailar a Isadora sino 'su doble', el embriagado Dionisos quien admira el rítmico y sensual balanceo de Anactoria, la amiga de Safo, personaje de las Heroídas de Ovidio" (83). De este modo, el poema adquiere una dimensión mítica, trascendiendo el tiempo y espacio real. En su crónica Darío hace referencia a Nietzsche y a ver la danza de Duncan desde la teoría de este filósofo, expresando:

(...) ya habéis visto cómo se proclama [Duncan] discípula el autor del Origen de las especies [Darwin]. Podía agregar al inevitable Nietzsche, catedrático de gozo dionisíaco, que mira en el baile la mayor manifestación de la libertad de la vida, como una acción enérgica y sublime. La danza para Miss Isadora no debe tener ningún artificio y debe ser nada más que una transposición o concentración del ritmo universal en el ritmo humano (1920: 151).

Darío y Duncan comparten esta influencia filosófica ya que para ella el filósofo alemán también fue un fuerte referente. Lo expresó repetidamente en frases como la siguiente: "Las dos fuentes del arte: Apolo y Dionisos" (Duncan, 2003: 151).

Como podemos observar, Duncan siguiendo a Nietzsche identifica el origen del arte en la Grecia clásica. Como mencionamos anteriormente, realizaba un culto hacia el arte clasicista identificando su concepción de belleza con la universalidad, tal como se puede apreciar en algunos de sus escritos como "El Partenón" y su ya citada conferencia "La danza del futuro":

(...) los griegos desarrollaron sus movimientos a partir del movimiento de la naturaleza (...) Esta es la razón por la que el arte de los griegos no es un arte nacional o característico, sino que ha sido y será el arte de toda la humanidad en todos los tiempos (Duncan, 2003: 59).

Sus mayores fuentes de estudio de la cultura clásica fueron los textos sobre música y teatro griegos a los que accedió en diversas bibliotecas de Londres y París, así como en los museos de estas ciudades, donde Duncan pasó días completos estudiando el movimiento de las figuras representadas en vasijas, bajo relieves y esculturas de la antigua Grecia y de las pinturas del Renacimiento. Esto fue identificado por Darío en su crónica: "Ella ha ido a Grecia, pasando por Italia" (1920: 154). Luego, la bailarina viajó a Grecia e incluso intentó fundar una escuelatemplo allí. Este viaje significaba ir a encontrarse con el "auténtico" origen de la belleza aunque, en realidad "era ir al encuentro de un Olimpo imaginario" (Tambutti, 2014: 16), era una evasión 
romántica. Respecto a estos viajes escribe Duncan en "Para hablar la lengua de la humanidad":

\begin{abstract}
Ciertamente, como todo artista de nuestro tiempo, me he inspirado en el arte griego, en tanto es el fundamento de toda nuestra cultura occidental. (...) en un período de dieciséis años he ido ocho veces a Grecia (...) porque vivir en Grecia es conocer el auténtico origen de la Belleza, la inspiración de mi arte. Pero eso no quiere decir que yo desee reconstruir las danzas antiguas(...) La Danza, que debe ser para nosotros un arte, no puede nacer más que de nosotros, de nuestras emociones y de la vida de nuestro siglo, como la danza antigua nació de las emociones y de la vida de los griegos antiguos (2003: 128).
\end{abstract}

Duncan, al igual que Darío, identificó el fundamento de la cultura occidental en la Grecia clásica. Ahora bien, Darío recupera esta elevación de la latinidad desde una cuestión genealógica -entiende a la cultura greco romana como el origen de la cultura latinoamericana, pasando por España como reducto espiritual-, recuperando la hispanidad y planteando la dicotomía entre civilización -latinos- y barbarie -sajones-. Paralelamente es un rechazo hacia los Estados Unidos (Real de Azúa, 1986: xiv). Por lo tanto, nos preguntamos si no sería una contradicción defender a una "yanqui" -tal como Darío se refiere a Duncan en su crónica-.

A partir de lo anteriormente expuesto en torno a la relación de Duncan con la cultura grecoromana y el modernismo, consideramos que Darío podría haber visto a la bailarina del mismo modo que a Walt Whitman, es decir, como una excepción. De hecho, opone la figura de Isadora a la de los "gigantes" bárbaros -“Morganes y Rockefellers"- cuando habla del país natal de la bailarina.

Dario rescataba a Whitman como un patriarca y profeta, quien tiene "civilización" y "cultura", mientras que en Estados Unidos solo reconoce "civilización", adelantos técnicos. También Isadora ensalzaba a Whitman como un profeta de su tierra y su "maestro de baile" junto a Rousseau y Nietzsche, mientras que repetidas veces expresó su queja hacia los Estados Unidos por no comprender ni "apreciar" su arte y recién "aprobar" su trabajo, una vez que triunfó en Europa, a donde viajó junto a su familia en un barco de ganado ya que no tenían dinero suficiente para costear sus pasajes (Duncan, 2003: 132-133).

Podemos observar su "devoción" a Whitman en el escrito "Veo bailar a América" -un claro intertexto con el poema "Oigo cantar a América" de dicho escritor-. En este, Duncan rescata la americanidad que ella considera digna de ser danzada: la giga irlandesa que aprendió de su abuela, mezclada con algo de "espíritu heroico" de los pioneros que batallaron contra los pieles rojas, algunos gestos de estos pueblos originarios y también un poco de "Yankee Doodle", todo 
eso junto a "la gran revelación espiritual" que dice haber encontrado en los versos de Whitman. Asimismo, evidencia en este escrito su racismo, no sólo delimitando una genealogía de su danza y de lo que considera que será la danza futura en la raza blanca-irlandesa, conquistadora-articulada con la tradición latina, sino que expresa abiertamente su aversión a la música y danza negra, diciendo que "El ritmo de jazz expresa al salvaje sudafricano", profetizando un "ritmo de América" futuro que "ordenará el caos en Armonía".

\begin{abstract}
Fuertes chicos y chicas con largas piernas bailarán esta música, y no las tambaleantes y simiescas convulsiones del Charlestón, sino un brillante y tremendo ascenso, un poderoso ascenso sobre las pirámides de Egipto, más allá del Partenón en Grecia, una expresión de la Belleza y del Esfuerzo como ninguna civilización ha conocido hasta ahora. Esta será la danza de América. Y esta danza no contendrá nada de la coquetería servil del ballet o de la convulsión sensual de Sudáfrica. Será limpia (...) Cuando los niños americanos bailen de esta manera, se convertirán en hermosos seres merecedores del nombre de Democracia. Esa será la América que danza (Duncan, 2003: 168-170).
\end{abstract}

Si bien no alcanza este grado, también hay una concepción de raza en los escritores modernistas como Darío. Real de Azúa identifica un "blanquismo" con el que se alentaba eso que ya estaba presente en las clases altas latinoamericanas, y recuerda palabras de Darío hacia los negros, quien los describe como "tan feos" y "pobres simios" (1986: xxiii). Sin embargo, Real de Azúa sostiene que en un nivel general, los ideales modernistas se movieron dentro de la ideología liberal conservadora imperante. Expresa que es casi imposible sostener que el modernismo haya conformado una "ideología", sino que más bien se construyó un "manierismo doctrinal" en América Latina a partir del modernismo. Así, identifica tres posiciones principales del modernismo respecto al contexto doctrinal más amplio: 1. cohonestaron las posturas y actitudes que muchos adoptaban, como la convicción elitista, las reservas a la democracia, los gestos racistas, la insistencia en la positividad de todo lo "aristocrático"; 2. ornamentaron la condición del liberalismo y el conservatismo de 1800, especialmente en su versión franco-británica; 3. despertaron latencias que abrieron esa sistematización ideológica, aquí se incluyen los rasgos de protesta social, el juvenilismo, el rechazo a los valores burgueses, el latinoamericanismo y antiimperialismo.

En cuanto a este último punto cabe mencionar que Duncan también compartía esta característica modernista. Se pronunció marxista y comunista, aunque de una manera superficial. Y llegó a fundar su escuela en la Rusia revolucionaria, aunque luego fracasó. Ese 
espíritu de revuelta sobrevive de manera acrítica en los relatos actuales de la visita de Duncan a la Argentina, como veremos a continuación.

Ahora bien, a partir de todo lo expuesto, indagamos si la visión de la cultura de los modernistas podría haber influido en la construcción de un horizonte de expectación en el público de danza que se estaba conformando en la Argentina. En el siguiente apartado desarrollaremos esta perspectiva reconstruyendo la recepción de Duncan en Buenos Aires en 1916, y cómo se conformó un relato acrítico de este momento, reproducido hasta la actualidad.

\section{Un modo de ver}

Según John Berger (2000), la mirada es una construcción histórica dada por los modos de ver creados a lo largo de los siglos a partir de las representaciones: "Nunca miramos sólo una cosa; siempre miramos la relación entre las cosas y nosotros mismos" (Berger, 2000: 14). En este sentido, intentamos reconstruir parcialmente, a partir de la prensa gráfica, esas miradas y representaciones -incluyendo el relato de la historiografía- de la visita de Duncan a la Argentina.

La narración acerca de dicha visita de la historiografía de la danza argentina se basa en la "incomprensión" de la bailarina y su arte, por parte del público local, lo cual concluyó con las funciones programadas y con la expresión agresiva de Duncan hacia los espectadores, llamándolos "negros" (Blair, 1989; Falcoff, 2008; Mogillansky, 2012). Asimismo, el relato incluye las anécdotas acerca de la interpretación de Duncan del Himno Nacional, envuelta en la bandera argentina -en el contexto de los festejos del Centenario de la Independencia- y su voluntad de bailar Wagner en tiempos de la Primera Guerra Mundial.

En su crónica de 1903, Darío advertía que "en nuestros centros latinos y católicos las danzas de Miss Isadora tienen que aparecer perfectamente inmorales" (1920: 150). Luego, durante las funciones de Duncan en el teatro Coliseo de Buenos Aires, los periódicos constantemente remarcaban que "El hecho de que sea discutida es la mejor prueba de que es interesante" ("Isadora Duncan", 14/07/1916). Esta idea de la artista "rara", rebelde, inspirada en la libertad, se reproduce en la historiografía de la danza argentina sin indagar en las fuentes sobre las presentaciones de la bailarina en Buenos Aires, trece años después de dicha crónica. A modo de ejemplo, citamos a continuación a Gabriela Mogillansky desde el campo de las letras, y a Laura Falcoff desde el de la danza: 
Este gesto [de avanzada por parte de Darío] se acentúa si tenemos en cuenta la escandalosa presentación de Duncan 7 [sic] años después, en 1910 [sic], en Buenos Aires, frente a un público posiblemente "dariano" y lector de La Nación, que obligó al empresario a suspender las funciones tras un escándalo protagonizado por la bailarina, quien insultó a una platea ruidosa al grito de "jindios incultos!" (Mogillansky, 2012: 2).

Los espectadores de su primer concierto, el 12 de julio, recibieron las danzas de Isadora un tanto fríamente. El público porteño estaba acostumbrado al lenguaje del ballet, aun en sus formas renovadoras (...) y encontró pobre y limitada la técnica de Isadora (...) Durante el concierto, algunos de los espectadores comenzaron a hablar en voz alta. Isadora dejó entonces de bailar y se dirigió a ellos de una manera airada, diciendo que ya le habían advertido que los sudamericanos no entendían nada de arte: Vousêtes que des nègres ("no son más que negros"), los increpó, usando una forma -négres-, muy despectiva. Este acontecimiento determinó que el administrador cancelara las funciones restantes (Falcoff, 2008: 234).

En estos dichos puestos en boca de Duncan, se observa la concepción de raza de la artista que expresamos anteriormente. Por ello resultan verosímiles y se han reproducido. Además, Falcoff menciona otros dos motivos por los que Duncan no fue bien recibida en Buenos Aires: el haber incumplido el contrato bailando el Himno Nacional en un "cabaret de estudiantes" según la propia Duncan (2006: 345-347)-, y el disgusto provocado a la audiencia por querer bailar Wagner y La Marsellesa. Estos se suman al motivo ya señalado por Darío acerca de la incomprensión de un público tradicionalista (6).

Sin embargo, si esta audiencia era dariana como hemos sostenido y como plantea Mogillansky, no debería haber incomprendido a Duncan. Por el contrario, el público lector de La Nación y de Darío, conocía a través de él y de otros escritores la danza de Isadora. El conocimiento de su estética se evidencia en las crónicas periodísticas de su visita que analizaremos a continuación.

Por lo tanto, proponemos que pueden ser otros los factores que hayan generado el rechazo del público local. Consideramos que, por un lado, el paso del tiempo (trece años desde la crónica de Darío hasta la presentación de Duncan en la Argentina) pudo haber modificado el gusto del público. Cabe aclarar que para ese entonces ya se estaba definiendo el camino de la práctica de la danza local. La conformación de un gusto definido por el ballet moderno se había iniciado, dejando de lado la rebeldía libre -romanticista- de aquellos precursores de la danza moderna, por una rebeldía más técnica y virtuosa, como aquella de Vaslav Nijinsky que formaba parte de 
la compañía Les Ballets Russes de Serge Diaghilev, quienes estaban en pleno auge en París y habían llegado a la Argentina recientemente -en 1913-, posicionando al ballet moderno como la estética fundante de la danza escénica argentina. Nijinsky representaba la nueva étoile del ballet -incluso repercutió en el ámbito local su casamiento en Buenos Aires durante su gira por Latinoamérica en 1913-, deviniendo en el nuevo símbolo del modernismo.

En nuestra búsqueda de fuentes nos encontramos con que Isadora se presentó por primera vez el miércoles 12 de julio de 1916 en el teatro Coliseo. Según nuestra reconstrucción el programa -en el que se intercalan las danzas de Duncan, con fragmentos musicales a cargo del pianista Maurice Dumesnil- fue el siguiente: Primera parte: 1. Allegretto de la sinfonía en re menor (orquesta solo) César Frank, Chopin; 2. Preludio en re bemol mayor (Dumesnil); Preludio 7, 2, 4, 6, 9, 21, 22; Estudios 13, 14, 12 (Dumesnil); Estudio 3; Nocturno en fa sostenido (Dumesnil); Nocturnes 2, último; Vals (Dumesnil); Valses en sol bemol. Segunda parte: 3. Sinfonía patética, Tchaikovsky; a. Introducción y allegro, orquesta solo; b. Allegro appassionato; c. Allegro vivace; d. Finale (lamento).

Por segunda vez bailó el viernes 14, y al ser un aniversario de la Revolución Francesa, incluyó en su programa a La Marsellesa. El programa fue el siguiente: Primera parte: 1. Himno nacional argentino por la orquesta; 2. La Marsellesa (orquesta); 3. Ifigenia en Aulide, ouverture (Gluck), orquesta; 4. Preludio número 5, Bélgica durante la guerra, Chopin; 5. Preludio número 9, Bélgica después de la guerra, Chopin; 6. Polonesa número 8, Chopin (Dumesnil); 7. Polonesa número 5 en do menor, Chopin; 8. Dos Mazurkas, Chopin (Dumesnil); 9. Dos mazurkas por Duncan, Chopin. Segunda parte: 10. Sinfonía patética, Tchaikovsky; a. Introducción y allegro, orquesta solo; b. Allegro appassionato; c. Allegro vivace; d. Finale (lamento); 11. La Marsellesa, Rouget de Lisle por Duncan.

Luego, si bien tenía programada una función para el domingo 16, la misma fue suspendida según informan los diarios, debido a que se encontraba "ligeramente enferma". Regresa al escenario el viernes 21 -en esta función las modificaciones del programa fueron las siguientes: 1. Ouverture de Alceste (Gluck); 2. Sonata op. 27 (Claro de luna), Beethoven; Valsesop. 39, Brahms; y por la segunda parte la sinfonía en la (nro. 7) de Beethoven-. Nuevamente se presenta el domingo 23 (no se especifica en los diarios el programa de la función) y el lunes 24. En esta última mostró su programa dedicado a Wagner. El programa fue el siguiente: Primera parte: 1. Tannhauser, ouverture (orquesta), Wagner; 2. Bacanale de Tannhauser, Wagner; 3. Traume, Wagner; 4. Maestros cantores, fragmento del tercer acto, Wagner. Segunda parte: 5. Murmullos de la floresta de Sigfrido(orquesta), Wagner; 6. El jardín de Klingsor de Parsifal, 
Wagner; 7. Encantamiento del Viernes Santo de Parsifal (orquesta), Wagner; 8. Preludio y muertede Isolda de Tristán e Isolda, Wagner.

Los diarios no hacen mención a que la inclusión de Wagner fuese un problema para la audiencia sino que expresan cuestiones como: “(...) llamó poderosamente la atención, tanto en su parte orquestal como por los comentarios mímicos de la artista" ("Isadora Duncan", 26/07/1916) o "Claro está que ninguna de estas obras es bailable en el sentido exacto de la palabra, pero sin duda el comentario mímico de la artista es interesante, ya que no convincente" ("Isadora Duncan", 24/07/1916). Si bien es cierto que el Maestro concertador y director de orquesta cambió para dichas funciones, tomando el lugar de Dumesnil, Ernesto Drangosch, no sabemos a partir de las fuentes periodísticas si la recepción del programa fue adversa por motivos políticos. Por el contrario, se evidencia en las fuentes periodísticas que aquello que no convenció fue la interpretación danzada de Duncan.

Finalmente, notamos que su última función fue el miércoles 26, repitiendo el programa wagneriano. Esta función fue anunciada como su "despedida", por lo tanto vemos que no fue un cese imprevisto de sus presentaciones, y que incluso repitió el programa dedicado a Wagner, lo que no hubiese sido posible si el público hubiera rechazado tal decisión, como se menciona en el relato de la historiografía de la danza argentina.

Los diarios expresan que Duncan dio un discurso en esa última función, diciendo primero que se dirigió al público lamentándose de su frialdad y explicando sus conceptos estéticos, y categorizando esta actitud por parte de Duncan de "entretenida" ("Isadora Duncan", 27/07/1916). Luego, al día siguiente y bajo el título de "Las extravagancias de la Duncan" (28/07/1916), El Diario agregó que fue un "'speech' inconveniente y grosero" y calificó su actitud de "insólita" y de "mala educación". Asimismo, este medio gráfico defendió al público calificándolo como portador de "cultura" y categorizando a la danza de Duncan que como "arte actual", "ya no conmueve a nadie" ("Las extravagancias de la Duncan", 28/07/1916).

En los programas de las funciones se puede observar quela selección musical refiere en su mayoría al romanticismo: Frank, Chopin, Tchaikovsky, Brahms, y por supuesto, Wagner. Esta preferencia evidencia lo planteado en el apartado anterior respecto a que si bien la estética de la danza de Duncan y la de los escritores modernistas latinoamericanos pueden compartir algunos rasgos, lo que prima en Duncan son las características del romanticismo. En oposición, la compañía de Diaghilev, en auge en ese momento entre el público de la danza y los intelectuales de élite de Buenos Aires, trabajaban con diferentes artistas modernistas: a modo de ejemplo, en música, podemos nombrar a Stravinsky y Prokófiev. 
Ahora bien, consta que Duncan se presentó en Buenos Aires durante seis funciones y no una o dos como parece sugerir el recuerdo de la bailarina. Y su discurso al que hace alusión Falcoff fue recién en su última función programada y no durante la primera presentación del programa wagneriano como insinúa la periodista, aunque no sabemos qué dijo Duncan en esta interpelación al público descripta como ofensiva. Si bien los periódicos exponen que Duncan no fue adorada ni ovacionada como en otros países, tampoco fue repudiada:

\begin{abstract}
El público, aun reconociendo el valor de las poses de Isadora Duncan, quedó decepcionado y se podía aplicar al caso la fabulilla del parto de los montes. ¡Se habían anunciado tales prodigios! Quizá Isadora en escenario más pequeño, con conferencias previas, el coro infantil, etc., dé impresión más definida. Lo de ayer fue [sic] algo brumoso a trechos iluminado por un rayo lunar. La figura tampoco cautivó. Sin embargo Isadora logró vivos aplausos y la más respetuosa consideración por parte de todos (...) (“Coliseo. Isadora Duncan", 13/07/1916).
\end{abstract}

En estas palabras se observa que aquella artista que llegaba como novedad a través de la crónica de Darío de 1903, para 1916 ya no consistía en un modelo de lo nuevo y lo moderno. Por el contrario, el público acostumbrado a seguir la moda parisina, ahora consideraba al ballet moderno, su virtuosismo y su estética, como aquel digno de sus escenarios.

Quizás fue incomprendida como vaticinaba Darío pero no sabemos si por aquellos motivos, ya que si bien el escritor se refiere a la sociedad como católicos que verían las danzas de Duncan como "inmorales", El Diario dice por ejemplo sobre la desnudez de la bailarina: "(...) es de notar que el ambiente de arte era tal que el desnudo ni alarmó pudores ni despertó recelos" (“Coliseo. Isadora Duncan", 13/07/1916). Además, como anticipábamos en el apartado anterior, la idea de un artista incomprendido parte de una fe de círculo, era constitutiva de la imagen de Duncan, al igual que los escritores modernistas latinoamericanos, por lo tanto, los periódicos y el público pueden haber anticipado e incluso esperado esta polémica, esta inmoralidad e irreverencia. Pero no resultó así, ya que su estética "ya no conmueve [conmovía] a nadie" ("Las extravagancias de la Duncan", 28/07/1916). Por el contrario, quienes en el momento eran el ejemplo de rebeldía y novedad eran los Ballets Russes. L'Après-midid'unfaune (1912) de Nijinsky era la nueva danza del "escándalo" por su erotismo y su abrupto alejamiento de la tradición del ballet clásico, y se había presentado recientemente en Buenos Aires, en 1913, sólo un año después de su fecha de estreno en París.

Esta preferencia de parte del público no quería decir que la artista fuese incomprendida. Observamos algunos interesantes escritos como el artículo "Modo de aprender la danza 
moderna o ultramodernista" ("Modo de aprender la danza moderna o ultramodernista", 13/07/1916) que intenta educar al público para la comprensión de las danzas de Duncan. Recordemos que Darío ya había etiquetado de "ultramodernas" a las danzas de Duncan. Aquí, el/la periodista que firma con sus iniciales A. J. M. da instrucciones para apreciar adecuadamente su danza, demostrando sus conocimientos acerca de la misma. Del igual modo, para la primera presentación de Duncan, los demás diarios advierten sobre la danza poco ortodoxa de la bailarina -"no es una bailarina en el sentido usual de la palabra" ("Miss Isadora Duncan", 12/07/1916)- y sobre el deber de asistir con buena predisposición, "con perfecta ingenuidad espiritual", "el alma abierta cándidamente a las emociones", libre de prejuicios ("Isadora Duncan. Su estreno", 12/07/1916). A través de estas expresiones como "espiritual", "alma", "emociones", dan cuenta que conocen el estilo de Duncan y su conexión religiosa con la danza que la emplaza dentro del romanticismo, tal como expusimos en el apartado anterior. Además, de este modo generaban suspenso en los espectadores, buscando el impacto de aquello polémico, que finalmente no fue tal.

Resulta interesante ver que estos argumentos se continúan utilizando para analizar la visita de Duncan, quizás a modo de sostener una representación determinada de su figura como artista rebelde, rara, incomprendida, moderna, sagrada, etcétera. En ese sentido, se exponen argumentos extra artísticos que no aparecen en las fuentes. Se intenta sostener la característica controversial de Duncan sin analizar críticamente su estética.

Sin embargo, lo que hemos encontrado en las fuentes es que lo artístico resultó central. Notamos en los escritos periodísticos que, por lo menos la prensa, conocía en profundidad y en complejidad a Duncan y no les era ajena su poética. Del mismo modo, proponemos que el público de élite de la época, ávido de novedad, si bien tenía muchas expectativas puestas en la presentación de esta bailarina, quizás haya preferido el modernismo del ballet y por ello se calificó a su danza como un arte que "ya no conmueve". Mientras que en la época de la crónica de Darío, Isadora era la última moda en París y todos alababan sus danzas, para 1913 estaba "pasada de moda" y el ballet moderno era lo que primaba. Los Ballets Russes representaban más ajustadamente aquellos valores múltivocos del modernismo (Real de Azúa, 1986), tales como el exotismo, el universalismo y el cosmopolitismo.

\section{Notas}


(1) Si tuviéramos que fijar el inicio de un posible relato histórico de la danza argentina, podríamos hacerlo en 1913 cuando llega a Buenos Aires la compañía de los Ballets Russes (1909-1929) dirigida por el empresario Serge Diaghilev.

(2) La danza moderna argentina se inicia alrededor de 1944 con el asentamiento en el país de Miriam Winslow, bailarina y coreógrafa norteamericana, quien creó el primer ballet de danza moderna -Ballet Winslow- en el que formaron los denominados "pioneros de la danza moderna", la primera generación de esta línea de danza en nuestro país.

(3) "La escuela de ballet actual, que lucha vanamente en contra de las leyes naturales de la gravedad o de la voluntad natural del individuo, y que trabaja en desacuerdo en su forma y movimiento con la forma y movimiento de la naturaleza, produce un movimiento estéril que no engendra ningún movimiento futuro, sino que muere en cuanto es hecho" (Duncan, 2003: 56).

(4) "En el año 100 antes de Jesucristo, en una de las colinas de Roma, se erigió una escuela llamada 'El Seminario de los Bailarines Sagrados de Roma'. Los alumnos de aquella escuela eran escogidos entre las familias aristocráticas (...) Cuando bailaban tenían que descender desde su colina hasta Roma, y en Roma participaban de ciertas ceremonias, y bailaban ante un pueblo para la purificación de aquellos que los contemplaban. Y los muchachos lo hacían con tal ardor gozoso y con tal pureza que su danza influía sobre la muchedumbre y la elevaba, como una medicina para almas enfermas. En estos bailes soñaba yo cuando, por primera vez, formé mi escuela" (Duncan, 2006: 321-322).

(5) Darío se refiere a la bailarina norteamericana radicada en Francia Loïe Fuller.

(6) Sin embargo, Duncan en su autobiografía sólo hace referencia al incidente del Himno y brevemente a la incomprensión por parte del público (2006: 345-347). Es Frederika Blair (1989) quien relata los hechos reproducidos por Falcoff y Mogillansky acerca del insulto de Duncan a los espectadores pero no especifica la fuente de dicho relato.

\section{Bibliografía}

Berger, J. (2000). Modos de Ver. Barcelona: Gustavo Gili.

Blair, F. (1989). Isadora. El retrato de la artista como mujer. Buenos Aires: Javier Vergara Editor.

Cadús, E. (2017). La consolidación de la práctica de la danza escénica durante el primer peronismo. Revista Digital de Estudios de Crítica Cultural Afuera, 17/18. Recuperado de https://drive.google.com/file/d/0By451f3DM8N3MDN2SIZfZjFOc0E/view

"Coliseo. Isadora Duncan" (13 de julio de 1916). El Diario, Buenos Aires.

Croce, M. (2013). Para animarse a leer a Rubén Darío. Buenos Aires: Eudeba.

Darío, R. (1920). Miss Isadora Duncan (1903) (pp.149-156). En Opiniones. Madrid: Mundo Latino.

Darío, R. (1924). La bailarina de los pies desnudos (1907) (p. 35). En El canto errante. Buenos Aires: Claridad.

Duncan, I. (2003). El Arte de la Danza y otros escritos. Madrid: Akal. 
Duncan, I. (2006). Mi Vida. Buenos Aires: Losada.

Falcoff, L. (2008). La danza moderna y contemporánea. En Durante, B. (coord.). Historia general de la danza en la Argentina (pp. 231-321). Buenos Aires: Fondo Nacional de las Artes.

"Isadora Duncan. Su estreno" (12 de julio de 1916). El Diario, Buenos Aires.

"Isadora Duncan" (14 de julio de 1916). El Diario, Buenos Aires.

"Isadora Duncan" (24 de julio de 1916). El Diario, Buenos Aires.

"Isadora Duncan" (26 de julio de 1916). El Diario, Buenos Aires.

"Isadora Duncan" (27 de julio de 1916). El Diario, Buenos Aires.

Jauss, H. R. (1976). Historia de la literatura como provocación de la ciencia literaria. Barcelona: Península.

"Las extravagancias de la Duncan" (28 de julio de 1916). El Diario, Buenos Aires.

"Miss Isadora Duncan" (12 de julio de 1916). La Nación, Buenos Aires.

"Modo de aprender la danza moderna o ultramodernista" (13 de julio de 1916). La Época, Buenos Aires.

Mogillansky, G. (2012). Danza y poesía: Rubén Darío, Isadora Duncan, César Vallejo. Actas del VIII Congreso Internacional de Teoría y Crítica Literaria Orbis Tertius, Centro de Estudios de Teoría y Crítica Literaria-IdIHCS/CONICET, Facultad de Humanidades y Ciencias de la Educación, Universidad Nacional de La Plata. Recuperado de http://citclot.fahce.unlp.edu.ar/viii-congreso/actas-2012/Mogillansky\%20Gabriela.pdf/view?searchterm=None

Pasolini, R. (1999). La ópera y el circo en el Buenos Aires de fin de siglo. Consumos teatrales y leguajes sociales. En Devoto, F. y Madero M. (Dir.). Historia de la vida privada en la Argentina. La Argentina plural 1870-1930 (Vol. 2, pp. 227-273). Buenos Aires: Taurus.

Real de Azúa, C. (1986). Modernismo e ideologías. Punto de Vista, IX(28), separata i-xlii. Buenos Aires.

Rivas Bravo, N. (1998). Un raro excluido de 'Los Raros'. En García Morales, A. (ed.). Rubén Darío: estudios en el centenario de Los Raros y Prosas Profanas (pp. 69-84). Sevilla: Universidad de Sevilla.

Tambutti, S. (2014). Segundo Momento. Espiritualismo naturalista, exotismo orientalista y trayectoria hacia el modernismo. Ficha de cátedra inédita de Teoría General de la Danza, Artes, Facultad de Filosofía y Letras, UBA.

Tambutti, S. (2011). El "nosotros" europeo. Clase universitaria del Seminario Reflexiones sobre la danza escénica en Argentina Siglo XX. Ficha de cátedra, inédita, FFyL, Artes, UBA. 
Eugenia Cadús. Isadora Duncan por Rubén Darío. Reflexiones sobre la recepción argentina de Duncan

Williams, R. (2000). Marxismo y literatura. Barcelona: Península. 